\title{
Um Sopro de cortar a respiração: a secreta melancolia de Tiago Rodrigues nos palcos franceses
}

\author{
ALEXANDRA MOREIRA DA SILVA
}

Título: Sopro. Texto e encenação: Tiago Rodrigues. Luz e cenografia: Thomas Walgrave. Sonoplastia: Pedro Costa. Figurinos: Aldina Jesus. Assistente de encenação: Catarina Rôlo Salgueiro. Interpretação: Isabel Abreu, Beatriz Brás, Sofia Dias, Vítor Roriz, João Pedro Vaz, Cristina Vidal. Produção: Teatro Nacional D. Maria II. Local e data de estreia: Cloitre des Carmes Cloître des Carmes - 71. a Edição do Festival de Avignon, 7 de Julho de 2017.

Os lugares da Arte podem afastar-nos do medo. ${ }^{1}$

JEAN-LUC LAGARCE

Vertigem. É sempre com uma sensação de vertigem que penso no Festival de Avignon. A 71. ${ }^{\mathrm{a}}$ edição não fugiu à regra. Não me refiro apenas às três semanas intensas do mês de Julho, nem aos 40 ou 50 espectáculos do Festival IN a que podemos assistir em 20 ou 30 espaços diferentes (teatros, capelas, ginásios, Palácio dos Papas...), e muito menos às cerca de 1000 companhias que apresentam mais de 1000 espectáculos no Festival OFF, ou aos cerca de 150 ooo espectadores que todos os anos circulam entre os locais dos espectáculos e as ruas da cidade, provocando verdadeiros engarrafamentos humanos. Também não estou a pensar, especificamente, nos milhares de cartazes e panfletos que revestem os muros, as casas, as janelas, as mesas dos cafés, os sinais de trânsito..., nem no frenesim com que esperamos a apresentação do pré-programa do Festival no final de Março, na aparente tranquilidade com que aguardamos a comunicação oficial do programa definitivo em Maio, na angústia que sentimos no dia da abertura da bilheteira ao público em meados de Junho ou no desespero de não termos conseguido bilhete para aquele espectáculo que tanto queríamos ver.

Não, não me refiro, de facto, a nada disto em particular, mas a tudo isto em geral, ou seja, à vertigem provocada pelas numerosas propostas daquele que é um dos mais antigos e mais visitados festivais de teatro 


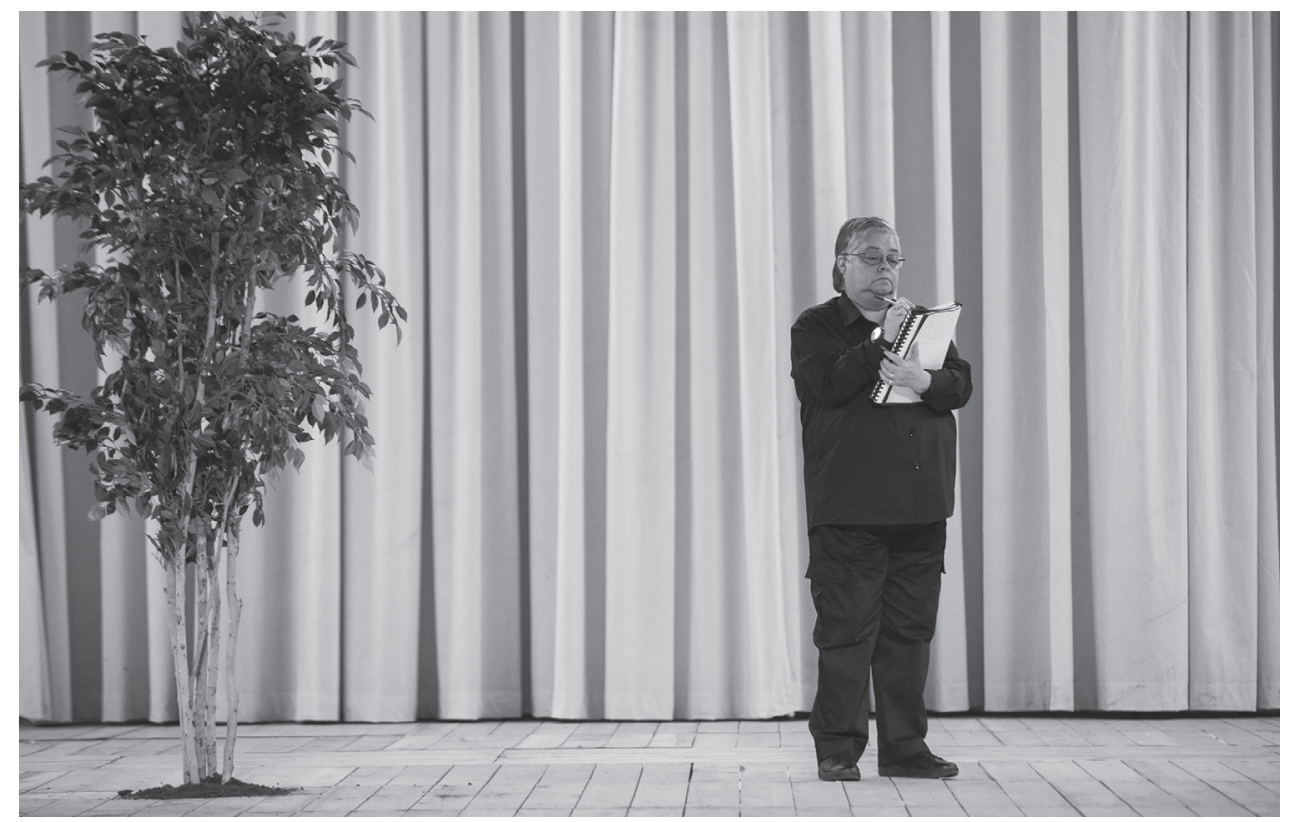

SOPRO, TEXTO E ENC. TIAGO RODRIGUES, TEATRO NACIONAL D. MARIA II, 2017 (CRISTINA VIDAL), [F] FILIPE FERREIRA

do mundo. Com o tempo, aprendi a seleccionar. Todavia, a sensação de perda - e de pena - é, evidentemente, incontornável.

Incontornável e imperdível foi, sem dúvida alguma, o espectáculo Sopro de Tiago Rodrigues, cuja presença com o íntimo e delicado António eCleópatra, magnificamente interpretado pelos actores, bailarinos e coreógrafos Sofia Dias a Vítor Roriz, havia já constituído um dos momentos altos do Festival em 2016, como o provaram a afluência massiva do público e o aplauso unânime da critica especializada. Na verdade, a presença de Tiago Rodrigues em Avignon tem sido dupla: em 2016, By Heart (2013) integra o Festival Contre Courant, evento criado há mais de dez anos à margem e simultaneamente em parceria com o Festival de Avignon. Dedicada essencialmente à criação contemporânea, esta proposta alternativa e pluridisciplinar apresenta todos os anos uma programação variada que contempla espectáculos de dança, teatro, performance, circo, música e poesia, na sequência dos quais são organizados debates e encontros com os artistas.

Em 2017, o texto de Tiago Rodrigues Tristeza e Alegria na Vida das Girafas $^{2}$, que a exigente crítica Armelle Talbot não hesita em classificar

2 «Tristesse et joie dans la vie des girafes», de Tiago Rodrigues, tradução e encenação de Thomas Quillardet, Chapelle des Pénitents Blancs, de 14 a 19 de Julho. 


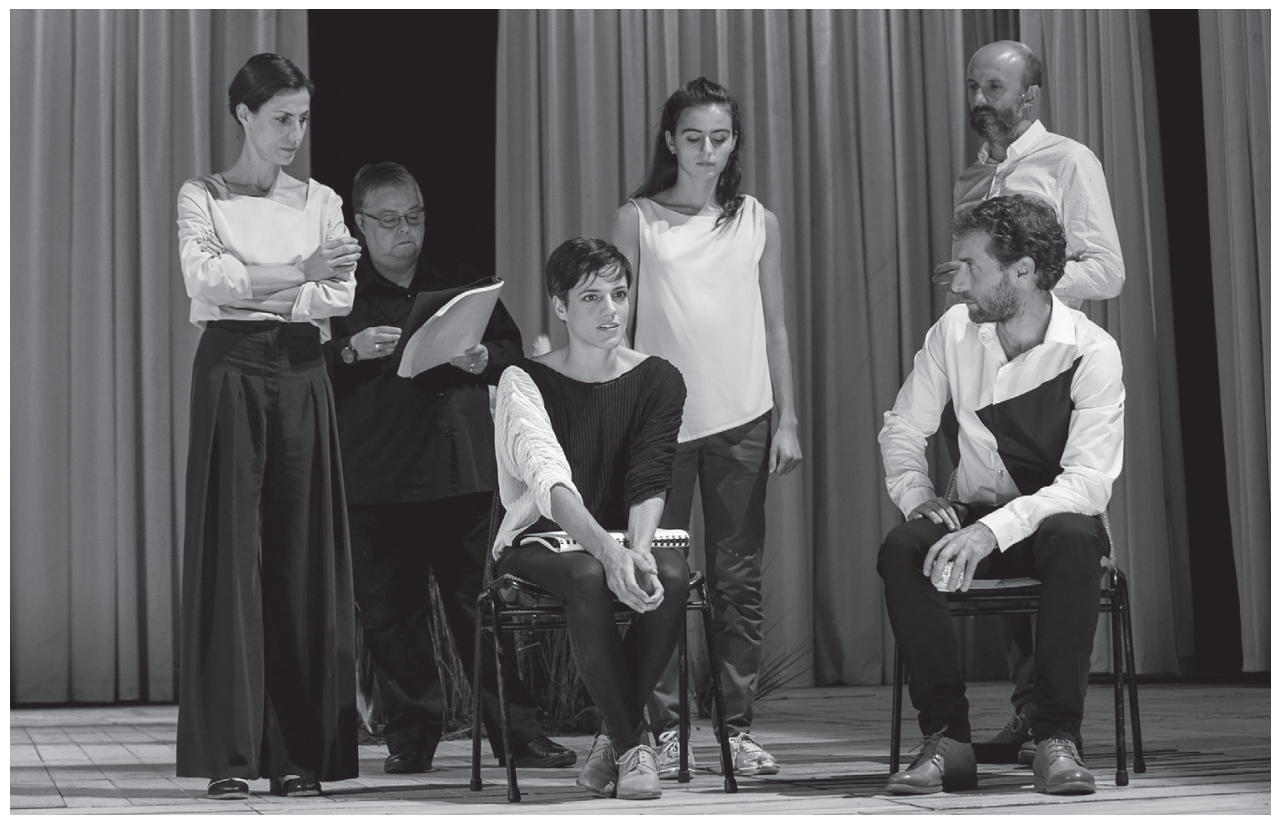

SOPRO, TEXTO E ENC. TIAGO RODRIGUES, TEATRO NACIONAL D. MARIA II, 2017 (ISABEL ABREU, CRISTINA VIDAL, SOFIA DIAS, BEATRIZ BRÁS, VITOR RORIZ E JOÃO PEDRO VAZ), [F] FILIPE FERREIRA

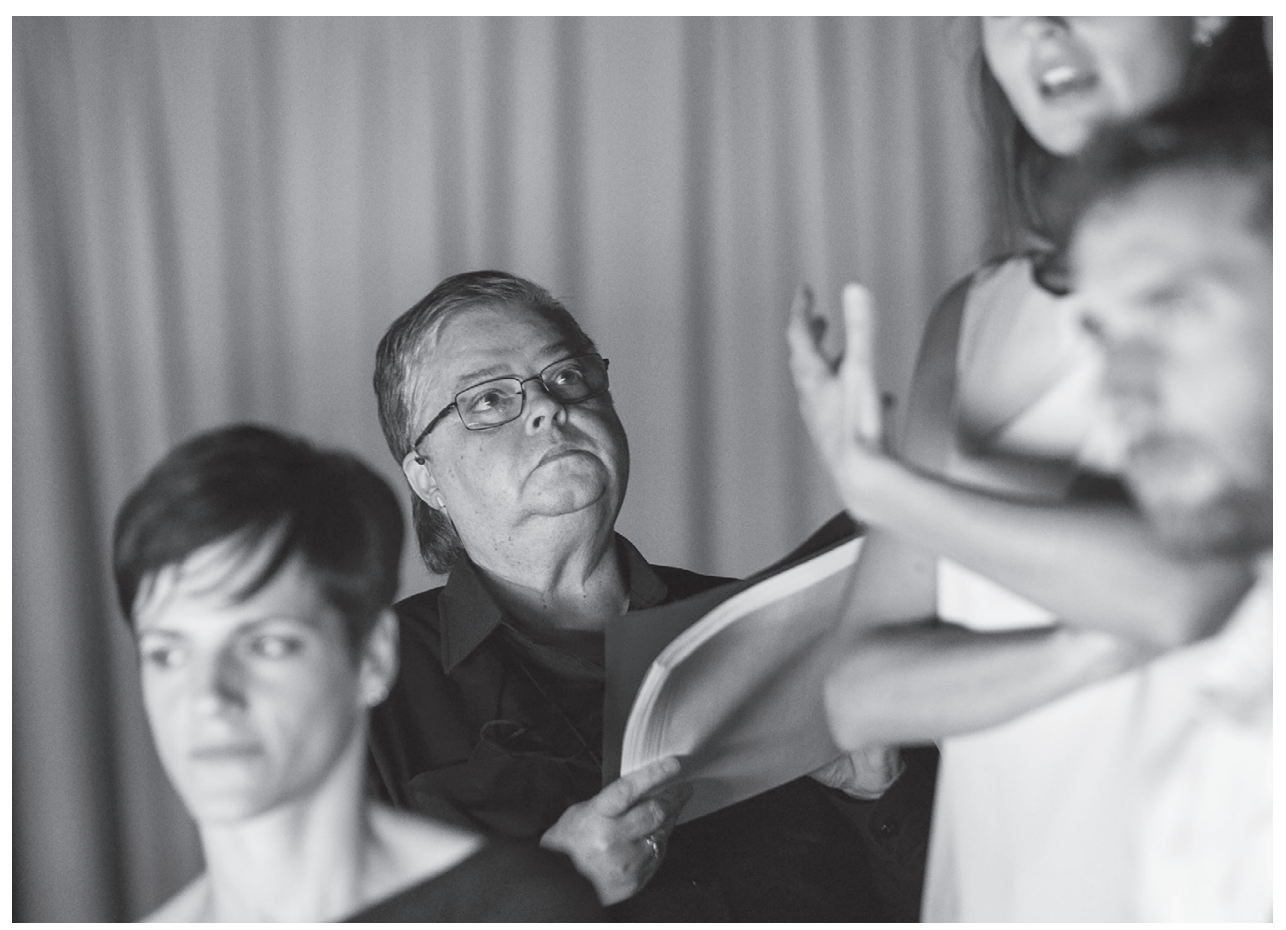

SOPRO, TEXTO E ENC. TIAGO RODRIGUES, TEATRO NACIONAL D. MARIA II, 2017 (SOFIA DIAS, CRISTINA VIDAL, BEATRIZ BRÁS, VITOR RORIZ), [F] FILIPE FERREIRA 


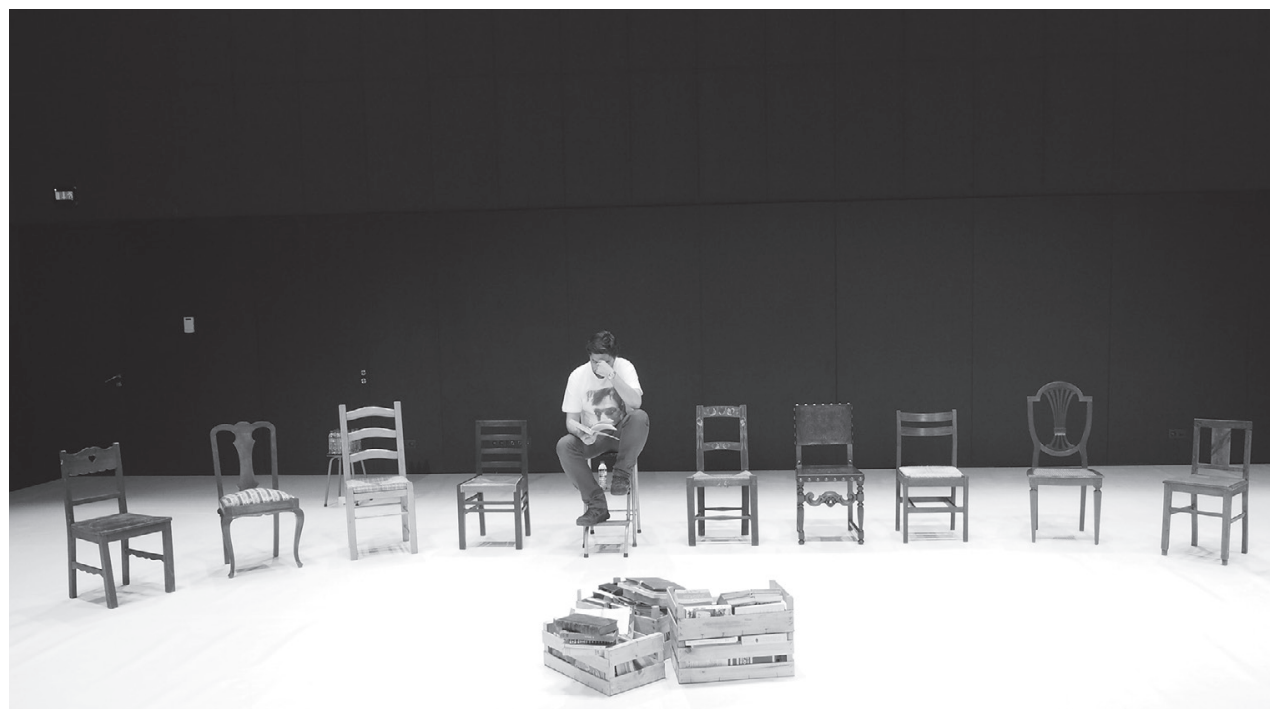

BY HEART, DE TIAGO RODRIGUES, TEATRO NACIONAL D. MARIA II, 2013 (TIAGO RODRIGUES), [F] MAGDA BIZARRO

como «uma pérola de malícia e de sensibilidade» (Le Figaro, 17/07/17), integra a programação «Teatro - público jovem» do Festival IN, numa delicada encenação de Thomas Quillardet, que é também autor da tradução da peça para francês. $O$ espectáculo viria a ser retomado e acolhido com grande entusiasmo num dos mais singulares teatros da capital francesa, Le Monfort, em Novembro passado.

De salientar, ainda, nesta $71 .^{a}$ edição do Festival de Avignon, a apresentação do livro Contemporary Portuguese Theatre, Experimentalism, Politics, and Utopia (Working Title)², no espaço da simbólica Maison Jean Vilar. Com coordenação de Rui Pina Coelho, esta obra conta com a participação de críticos e investigadores portugueses que propõem uma reflexão atenta sobre o panorama do teatro português contemporâneo. Traduzido e publicado em inglês, este livro importante inclui um conjunto de referências bibliográficas e uma cuidada iconografia de inegável interesse e utilidade para um público estrangeiro, nem sempre familiarizado com os palcos portugueses.

De Avignon, aos festivais mais periféricos, até à circulação pelas diferentes cidades do norte a sul do país, a obra dramática e teatral de

3 Rui Pina Coelho (org.), Lisboa, TNDMII \& Bicho do Mato, 2017 (apresentação na presença de Rui Pina Coelho e Tiago Rodrigues, Maison Jean Vilar, 9 de Julho de 2017). 


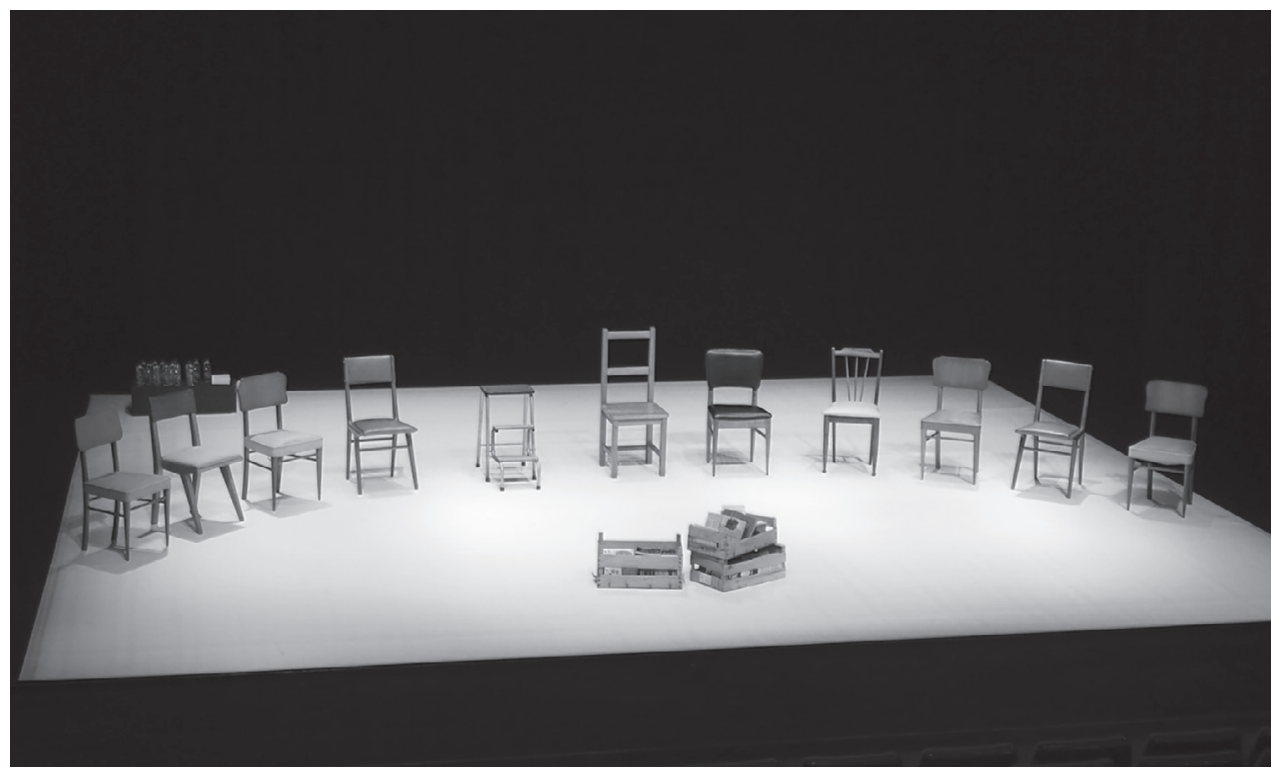

BY HEART, DE TIAGO RODRIGUES, TEATRO NACIONAL D. MARIA II, 2013 (TIAGO RODRIGUES), [F] MAGDA BIZARRO

Tiago Rodrigues tem tido um impacto importante na cena francesa contemporânea. Percurso feito de encontros e de afinidades electivas, de travessias, de intensidades e de vibrações diversas, o trabalho do actual director do TNDMII afirma-se como um lugar privilegiado da tão necessária partilha do sensível. Homem de teatro, cidadão do mundo, Tiago Rodrigues cria uma obra singular a partir daquilo a que poderíamos talvez chamar, com Hélène Cixous, «uma língua-torre com vista sobre o mundo inteiro, uma língua-farol [...], olhares lançados sobre todas as torres da humanidade, na torre mil línguas, os mil livros do mundo» (2016: 42). Entenda-se: torre aberta ao outro, torre de memória, de partilha e de resistência, que atravessa fronteiras - que aberta ao mundo se faz mundo.

Depois de Avignon, valerá, então, a pena traçar, ainda que rapidamente, a trajectória de Tiago Rodrigues pelos lugares públicos, e outros talvez mais clandestinos, de um país onde preservar o espaço da arte e da criação ainda vai sendo uma forma de lucidez e de vigilância - «porque sabemos bem que os tempos fáceis não existem» (Rodrigues, 2017: 140). 


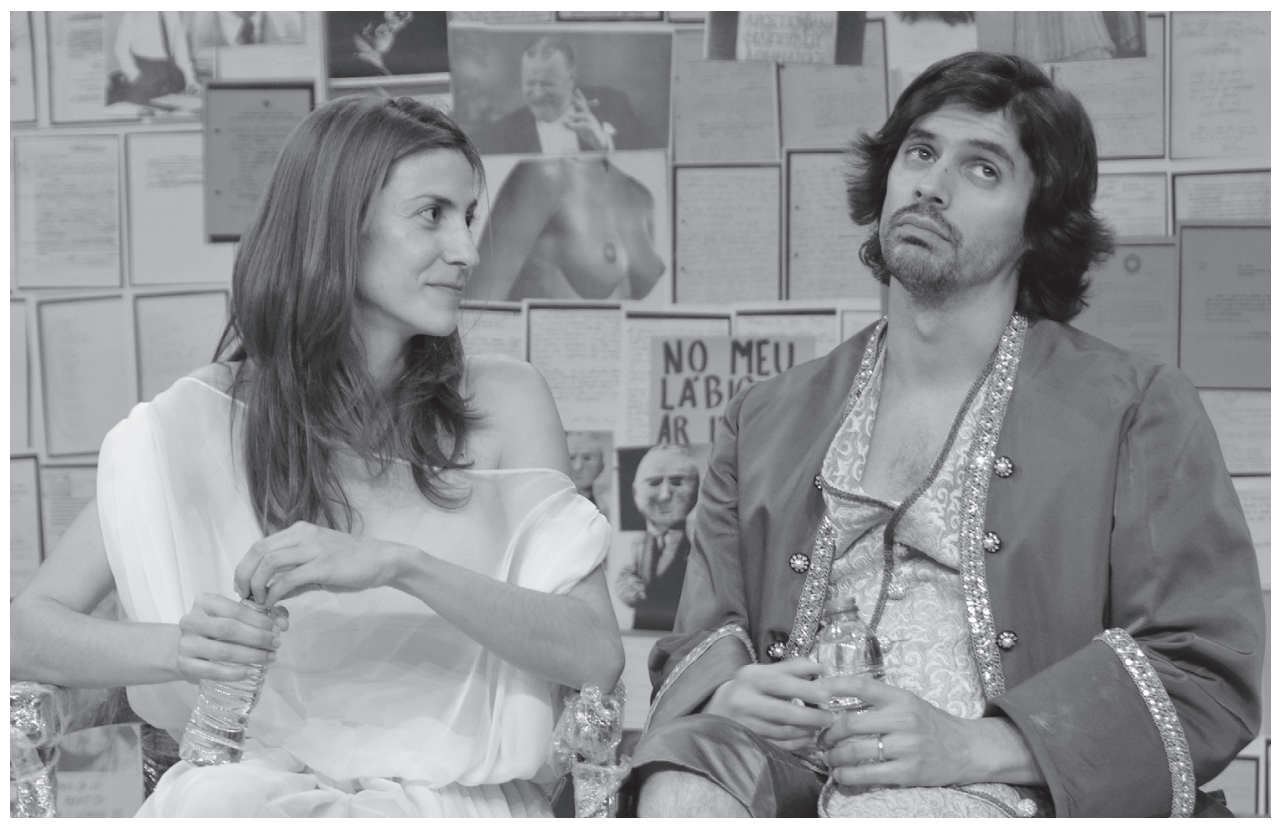

TRÊS DEDOS ABAIXO DO JOELHO, TEXTO E ENC. TIAGO RODRIGUES, MUNDO PERFEITO (ISABEL ABREU E GONÇALO WADDINGTON), [F] MAGDA BIZARRO

Dizer aos outros [...] a graça suspensa do encontro.

O encontro de Tiago Rodrigues com o público francês acontece, num primeiro momento, graças à célebre companhia flamenga Tg STAN, com quem o artista português colabora desde $1998 .{ }^{5}$ Cúmplices do Théâtre de la Bastille e do seu director Jean-Marie Hordé, é neste teatro situado na movimentada rue de la Roquette que Tiago Rodrigues tem apresentado os seus espectáculos mais recentes e onde desenvolveu, em 2016, a Ocupação Bastilha, projecto de pesquisa teatral participativa entre actores, funcionários do teatro e cerca de 70 espectadores.

Em 2008, Tiago Rodrigues apresenta o seu primeiro trabalho pessoal em França, ainda que resultante de um cruzamento de cumplicidades e de universos artísticos com origens bastante diferentes. A convite de Mark Deputter, então director do Festival de Alcântara, dois artistas libaneses,

4 Jean-Luc Lagarce, op. cit. p. 33.

5 Como Ela Morre é a mais recente colaboração entre Tiago Rodrigues e a companhia flamenga. Texto e conceito de Tiago Rodrigues, com Frank Vercryssen, Isabel Abreu, Jolente de Keersmaker e Pedro Gil, Produção TgSTan e TNDMII, 2017. 
Rabih Mroué e Tony Chakar, e um português, Tiago Rodrigues - a quem Aude Lavigne chamou «a fina flor do teatro contemporâneo» ${ }^{6}$ - desenvolvem um projecto intitulado Yesterday's Man (2007), apresentado no Théâtre de la Bastille, no âmbito do Festival de Outono com o título francês L'homme d'hier. Em Junho de 2013, Três dedos abaixo do joelho é programado no Théâtre des Abesses, integrando a $4 \cdot{ }^{\mathrm{a}}$ edição do Festival «Chantiers d'Europe Lisbonne-Paris». Apesar de Junho ser já o final da temporada teatral parisiense, o espectáculo não passa despercebido. A crítica reage não só ao espectáculo como à construção do texto, ao gesto do autor-arqueólogo que, sob os sedimentos dos textos dos censores, encontra matéria para falar do poder da arte teatral.

Mas será no ano seguinte, com By Heart, que o fenómeno Tiago Rodrigues se vai instalar definitivamente nos palcos franceses. Com texto, encenação e interpretação do artista português, o espectáculo conquista não só o público como também a critica e os programadores: Tiago Rodrigues é, desde então, o artista que todos querem acolher. O êxito inquestionável da primeira passagem pelo Festival de Avignon, em 2016, com António e Cleópatra cria grandes expectativas num público que aguarda com real interesse e curiosidade o novo espectáculo, Souffle, em 2017. Em 2016, By Heart tem nova série de apresentações na capital francesa, enquanto António e Cleópatra passa pelo Centre National Dramatique de Montpellier, pelo Festival Terres de Paroles - que programará igualmente o espectáculo Entrelinhas, de Tiago Rodrigues e Tónan Quito - para ser finalmente apresentado no Théâtre de la Bastille, desta vez em língua francesa. Esta nova versão de António e Cleópatra fará uma importante tournée ao longo de 2017, percorrendo onze cidades e algumas das mais importantes cenas francesas.

Ainda em 2016, Tiago Rodrigues ocupa o teatro da rue de la Roquette com o projecto «Ocupação Bastilha» que incluiu três apresentações de um work in progress, cujo resultado final teria como título «Je t'ai vu pour la première fois au théâtre de la Bastille». Acrescente-se ainda a criação francesa de Bovary com os actores Jacques Bonnaffé, David Geselon, Grégoire Monsaingeon, Alma Palácios e Ruth Vega Fernandez, espectáculo que pudemos (re)ver, em Março de 2018, no mesmo teatro.

Importante será dizer que a presença assídua de Tiago Rodrigues nos palcos franceses - mas também na imprensa, nos media, em particular nos diversos programas radiofónicos da France Culture, nos encontros e

6 http://mutualise.artishoc.com/bastille/media/5/dossier_I_homme_d_hier_indd.pdf. 


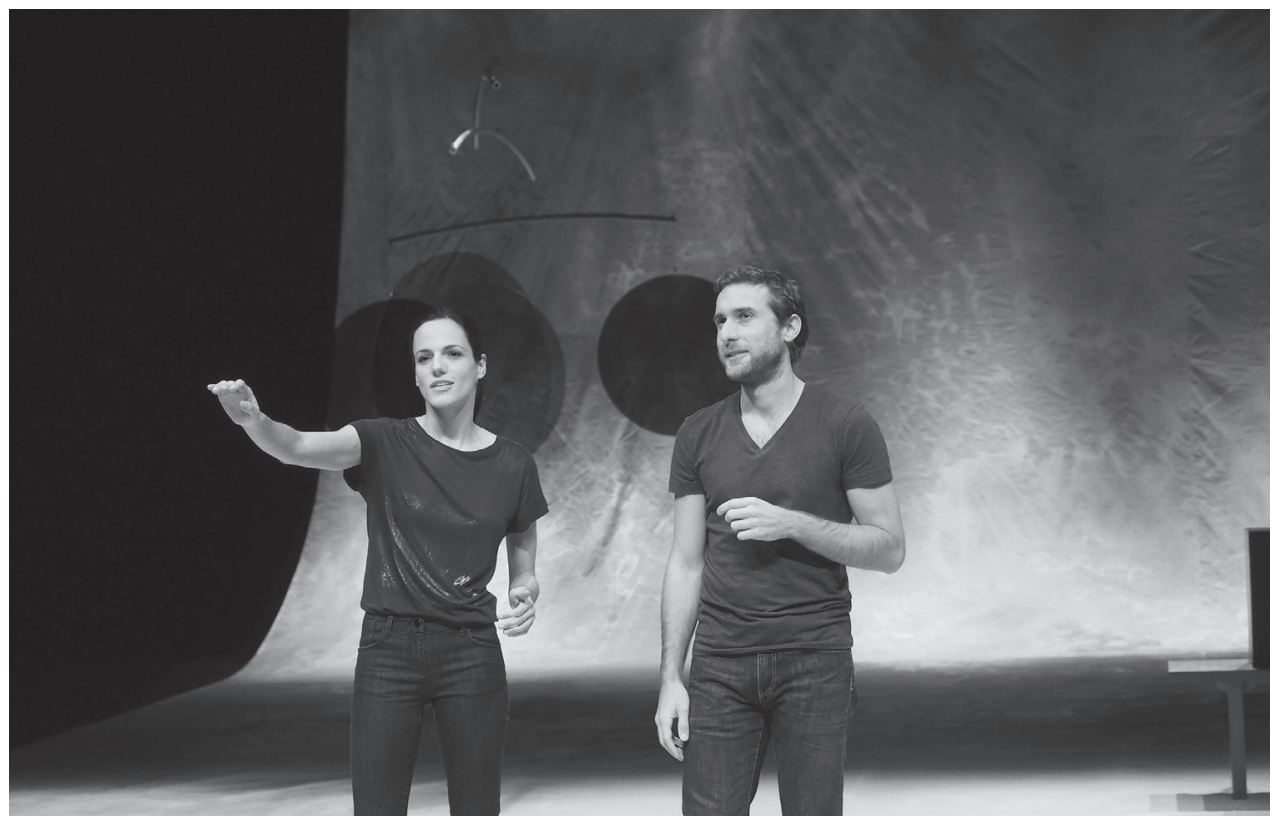

ANTÓNIO E CLEÓPATRA, DE TIAGO RODRIGUES, MUNDO PERFEITO, 2014 (SOFIA DIAS E VITOR RORIZ), [F] MAGDA BIZARRO

debates organizados nos teatros ou nas universidades - muito tem contribuído para o real interesse que se tem vindo a manifestar em diversos sectores pelo teatro português contemporâneo. Certo, o caminho é longo, mas a mudança é já notória: por aqui, os olhares atravessam mais facilmente os Pirenéus. E não param em Madrid, bem pelo contrário...

Homem de teatro, Tiago Rodrigues é, antes de mais, autor. É do encontro com as palavras, com as línguas e in fine com a literatura que nascem os diferentes projectos artísticos e poéticos do artista português. Dito de outra forma é com estes «discretos ocupantes da memória» (Rodrigues, 2015: 13) que ele vive, convive diariamente e cria. Os seus espectáculos são, aliás, frequentemente interpretados em várias línguas, o que obriga os actores a abandonarem o conforto do monolinguismo. «Eu sou pelo bilinguismo como língua mínima, afirma Cixous, Pelo menos duas. E vemos o mundo de forma diferente. [...] Estamos destinados politicamente, eticamente, a ultrapassar as fronteiras, o fechamento nacional» (2016: 91). O polilinguismo surge, assim, no trabalho de Tiago Rodrigues, como um elemento fundamental e constitutivo dessa língua livre e porosa que

7 Tiago Rodrigues, «Préface», By Heart, Besançon, Les Solitaires Intempestifs, 2015, p. 13. 


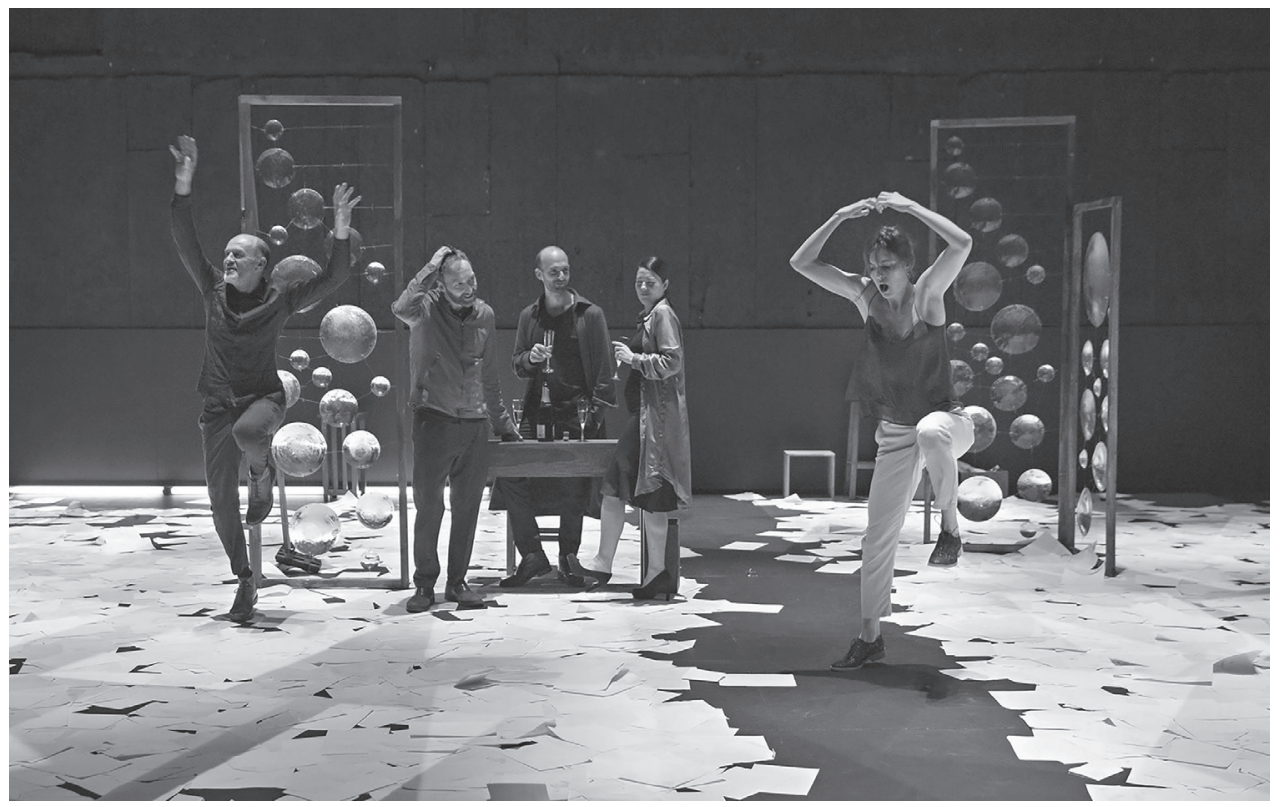

BOVARY, TEXTO E ENC. TIAGO RODRIGUES, THÉÂTRE DE LA BASTILLE, 2017 (JACQUES BONNAFFÉ, GRÉGOIRE MONSAINGEON, DAVID GESELSON, RUTH VEGA-FERNANDEZ E ALMA PALACIOS, [F] PIERRE GROSBOIS

é a língua do teatro. $\mathrm{E}$ depois, «as línguas são anjos com memória», diz ainda a autora francesa, guardam e repetem os passos, o sopro de Ésquilo, de Sófocles, de Shakespeare, de Molière, de Racine, de Flaubert, de Tolstói, de Tchékhov, de António Patrício, de Jean-Luc Lagarce... de todos esses fantasmas lentos e desenvoltos a quem Tiago Rodrigues dá voz nas suas peças como gesto poético e político, ou seja, de criação e de transmissão. Não será esta a mais bela forma de preservar «os lugares onde podemos ouvir o vento, o sopro do pensamento, o espírito do lugar, o momento breve e irrepetível em que nos vemos pela primeira vez. E sobretudo, (de) não morrer» (Rodrigues, 2017: 140)?...

Contudo, a escrita de Tiago Rodrigues não repousa naquilo a que poderíamos chamar uma técnica intertextual, não é apenas uma escrita palimpsestuosa, uma reescrita por cima do manuscrito, muito embora possa também recorrer a este gesto tão frequentemente utilizado na dramaturgia contemporânea. Na obra de Tiago Rodrigues, o encontro com o outro, esse momento breve e irrepetível, transforma-se não raras vezes em diálogo interior ${ }^{8}$, num diálogo virtualmente sem fim e quase contínuo, 
numa parceria permanente com as vozes que vamos herdando, que são talvez a nossa mais bela e profunda herança, espectral, íntima e tão necessária. É este dialogo interior, este trazer o outro em si-o outro que ele não $e ́$, que precede e orienta a escrita - a escrita amorosa de Tiago Rodrigues. Disto mesmo são testemunha, para citar apenas um exemplo, os nove cantos de António e Cleópatra. Não se trata apenas de uma reescrita, e muito menos de um inventário de palavras arrancadas à tragédia shakespeariana, mas de uma verdadeira e assumida anexação onde é visível a dependência poética dos dois textos e, ao mesmo, tempo, a independência de uma linguagem pessoal e profundamente livre, destinada, neste caso concreto, à liberdade dos corpos e das vozes dos dois intérpretes. Neste sentido, António e Cleópatra é um texto de Tiago Rodrigues, mas é também Shakespeare naquilo em que a poesia de Tiago Rodrigues o pode mudar. «Haverá algo mais perturbador, mais tranquilizador, do que a revinda: o que acabou não acabou. Reencontramos o que julgávamos perdido. Como um amor perdido, repudiado, e que volta, que festa, que vitória sobre as forças de dispersão: é o motor de António e Cleópatra» (Cixous, 2016: 53). E é também um dos motores da escrita de Tiago Rodrigues ${ }^{9}$, a herança, o legado, a revinda, o sopro, claro, o sopro dos fantasmas, dos heróis que povoam o teatro da nossa história, da nossa memória. «Escrever», dizia Tiago Rodrigues recentemente, «é poder salvar Antígona no final.» Ou ainda dar a palavra à ponto e fazer o público ouvir a outra Berenice - a da sombra - em sete versos.

Nós, os heróis ${ }^{10}$

JEAN-LUC LAGARCE

«Se em mim, ó Alma, vive mais lembrança»... Foi este verso camoniano em que pensei durante o espectáculo. Mas foram os versos de Racine, na tradução de Vasco da Graça Moura, que me acompanharam, a mim e a todos os espectadores em estado de graça, à saída de Sopro de Tiago Rodrigues: «Amei, Senhor, amei, e quis só ser amada./ Confesso, porém, me senti hoje alarmada...»

9 As traduções dos textos de Tiago Rodrigues (Tristesse et joie dans la avie des girafes, tradução de Thomas Quillardet, By Heart, Bovary, e Antoine et Cléopâtre, tradução de Thomas Resendes) estão publicadas na editora Les Solitaires Intempestifs. Em 2018, serão publicadas as traduções de Sopro e de Como Ela Morre na mesma editora, também com tradução de Thomas Resendes. 
Sei bem que não é habitual começarmos a falar de um espectáculo evocando o fim. Não há sequer, no texto ou no espectáculo, uma progressão linear, uma história, uma reviravolta inesperada em que as personagens passem de um estado a outro, por exemplo, da felicidade à infelicidade - ou vice-versa. Dito de outra forma, não há qualquer razão dramatúrgica que nos leve a desvendar o final do espectáculo no início de um texto que será menos uma crítica do que um comentário. A razão é íntima, como íntimo é o teatro de Tiago Rodrigues. Ou seja, intimamente, secretamente, ao longo do espectáculo, vai aumentando em nós, espectadores avisados e menos avisados, o desejo de ouvir a voz da ponto Cristina Vidal. É por aqui que eu gostaria de começar esta breve reflexão. Desejamos que ela fale, que nos dirija algumas palavras, dessas que tão bem sussurra aos actores - esperamos que isto aconteça. Porém, nada no espectáculo nos diz que isto vai acontecer, bem pelo contrário. Desde o início, Cristina Vidal está em cena, na luz, como estaria na sombra dos bastidores: vestida de negro, texto na mão, lábios murmurantes, atenta, sempre atenta aos actores, como um mestre-de-cerimónias habituado a alimentar a máquina do teatro com um simples sopro, desde a obscuridade. $\mathrm{E}$, de repente, já no final, aquilo que tanto desejamos - o nosso segredo-é-nos oferecido, revelado: Cristina Vidal, sozinha em palco, vem à boca de cena e diz sete versos de Racine: «Levai longe de mim ferros, suspiros, zelo...» Se dúvidas houvesse, Sopro mostra-nos o quanto o teatro de Tiago Rodrigues se constrói, também, a partir e com a participação do espectador, ou seja, o quanto as imagens do espectáculo vão dando forma aos nossos desejos, ao mesmo tempo que, através do desejo, nos vamos apropriando dessas mesmas imagens. O gesto não é nunca de manipulação - não há qualquer sentimentalismo nos espectáculos do artista português. Trata-se, isso sim, de um gesto de colaboração que o espectáculo vai alimentando generosamente, ao solicitar a memória do espectador. Atentemos no seguinte exemplo: os dois primeiros actores a entrar em palco são Sofia Dias e Vitor Roriz, eles serão a «Ponto» e o «Director», devidamente pontados por Cristina Vidal. E ali, naquele preciso momento, é como se nos dissessem: lembram-se de António e Cleópatra? Lembram-se?... Lembram-se de nós, da nossa história?... Foi esta a primeira sensação que me ficou de Sopro: a de uma solicitação permanente da memória do público, que cria uma proximidade cada vez maior com a «memória viva» que é Cristina Vidal, chegando mesmo a desejar ouvir a sua voz.

Sopra um vento ligeiro no palco a céu aberto do Claustro des Carmes. O cenário, de uma assumida austeridade poética e teatral, é da autoria de 


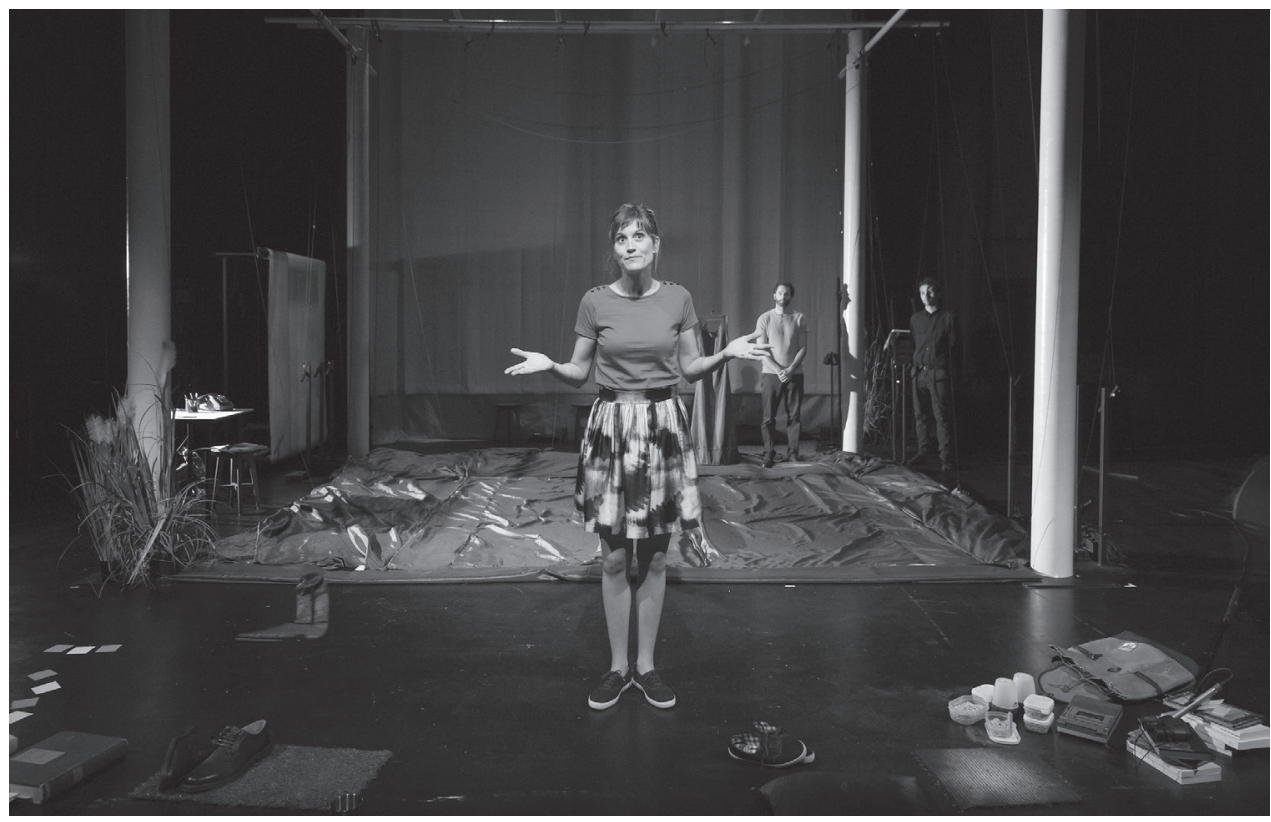

TRISTESSE ET JOIE DANS LA VIE DES GIRAFFES, DE TIAGO RODRIGUES, ENC. THOMAS QUILLARDET, 2017, [F] CHRISTOPHE RAYNAUD DE LAGE

Thomas Walgrave, que assegura também um subtil trabalho de luzes, e muito contribui para a criação de uma atmosfera quase diáfana, servindo com justeza o movimento da palavra murmurada de Cristina Vidal, cantada - o intermédio musical onde Sofia Dias interpreta a canção «Wild Is the Wind» é de uma notável delicadeza-ou simplesmente dita, aveludada, nas bocas dos cinco actores que integram o elenco do espectáculo: Beatriz Brás, Isabel Abreu, João Pedro Vaz, Sofia Dias e Vítor Roriz. Uma chaise longue lembra os veludos escarlates das tradicionais plateias dos teatros; o granito do que resta do Claustro des Carmes quebra, pontualmente, o esvoaçar distraído das cortinas brancas que envolvem a cena; ao fundo, a torre sineira. Aqui e ali, plantas e outras ervinhas invadem as quarteladas do palco. Um teatro não verdadeiramente em ruínas, mas provisoriamente fechado, abandonado, talvez à espera. Entra Cristina Vidal com o texto na mão. Seguir-se-ão os outros actores, que, delicadamente, como que suspensos, aéreos, etéreos, de uma leveza quase espectral - note-se a importância dos figurinos discretos e leves na proposta de Aldina Jesus-, virão habitar este espaço fantasmagórico ou simplesmente onírico.

É nos vestígios deste teatro que Tiago Rodrigues cria um dispositivo teatral onde, através da figura muitas vezes esquecida, quase 


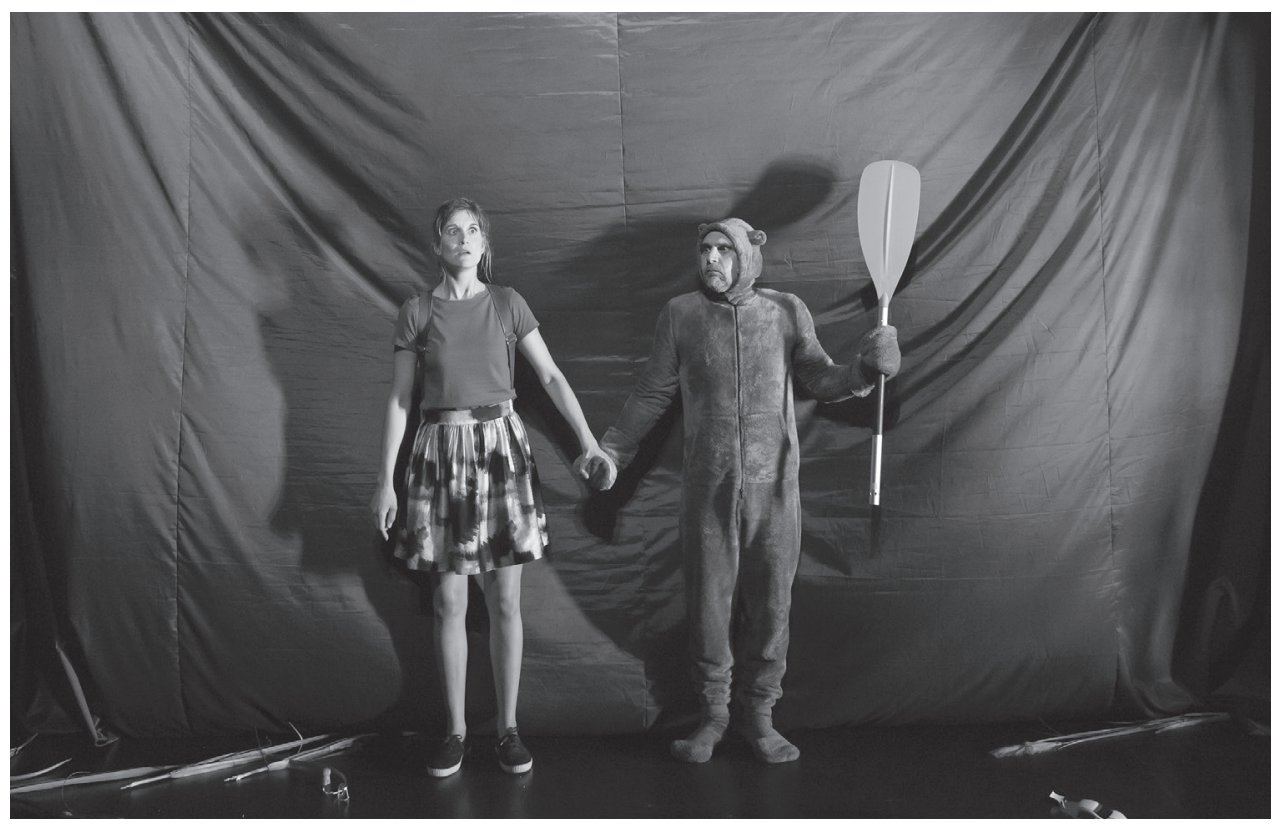

TRISTESSE ET JOIE DANS LA VIE DES GIRAFFES, DE TIAGO RODRIGUES, ENC. THOMAS QUILLARDET, 2017, [F] CHRISTOPHE RAYNAUD DE LAGE

desaparecida do ponto, a memória do teatro e dos seus fazedores (autores, actores, directores...) encontra um espaço de sobrevivência. O gesto é benjaminiano. A Ponto é o génio do lugar que silenciosamente arquivou, ao longo de toda uma vida, um sem-número de histórias de um determinado teatro. O director é aquele que, ao inscrever-se no presente, o vê permanentemente como um estaleiro de escavações arqueológicas onde importará fazer surgir o passado, a memória do teatro, os seus fantasmas, os seus espectros. Se, como refere Agamben, «a espectralidade é uma forma de vida. Uma vida póstuma ou complementar, que começa apenas quando tudo acabou e que tem, por isso, perante a vida, a graça e a astúcia incomparável do que se consumou [...]» (2010:53,54), talvez a memória do teatro seja uma memória espectral, habitada por espectros, e portanto uma forma de vida - e uma forma de resistência.

É neste teatro desactivado que se tornam perceptíveis, dispostos, dois movimentos que se cruzam e se completam: a narrativa de vida de Cristina Vidal, da infância ao momento em que aceita o convite do director para integrar o espectáculo, onde o real vai sendo interceptado pela ficção dos diferentes momentos das suas histórias de teatro; $\mathrm{e}$ a narrativa da origem do próprio espectáculo, que, sob a forma de uma simples conversa de café, 
se apresenta como uma reflexão in progress sobre o gesto de criar e sobre as complexas relações entre a arte e o real. Interrogar o arquivo é sempre uma tentativa de organizar um real a reconstruir, ainda que seja no interior de uma ficção. E é exactamente isto que o Director faz. No cruzamento das duas narrativas, surge a desordem construtiva das histórias de teatro, que permitem dar forma ao trabalho invisível de Cristina Vidal, e actualizar as preocupações do Director: «a ficção torna-se real e dá à realidade um poder ficcional $\gg^{11}$.

A palavra, essa, é constantemente transferida para os actores. Toda a dramaturgia do espectáculo repousa, aliás, neste desdobramento de personagens e de papéis, neste ser através do outro que os cinco actores assumem magistralmente: eles são Dinis e Isabel, de António Patrício, Verchínin, Olga, Irina, Macha de Tchékhov e Harpagão de Molière, ou ainda Antígona e Ismena de Sófocles, mas também a Directora, o Director e a Ponto, claro. Tudo pontado-e delicadamente orquestrado-por Cristina Vidal: «São muitos anos, muitas pessoas, muitas peças. Tudo se confunde, os nomes dos actores e os nomes das personagens», diz a Ponto (Rodrigues, 2017:116). A realidade e a ficção... Numa das cenas mais paradigmáticas do espectáculo, Isabel Abreu e João Pedro Vaz (extraordinários, como sempre) são a Directora e Verchínin, o actor, mas também a Directora e o médico que analisa a evolução da doença da primeira. Representam uma conversa no consultório do médico, repetem-na, retomam-na, como se um ensaio se tratasse e mostram-nos o quanto precisamos da ficção para enfrentarmos a realidade, e da realidade para alimentarmos a ficção: «Pegamos de "E se correr mal?". Mas fala mais baixo, mais pausas, mais sorrisos.» (ibidem: 125)

De alguma forma, a Ponto e o Director são duas faces da mesma moeda: ambos vivem «na fronteira [...] no lugar de passagem entre os bastidores e o palco, na ponte que liga a margem da realidade à margem da ficção.» (ibidem: 84). Ambos sabem que o que fazem no teatro (também) é a realidade.

Sopro é um espectáculo feito de subtis e sublimes fragmentos de um discurso amoroso ${ }^{12}$. Em filigrana, a secreta melancolia dos heróis e das suas mais secretas batalhas.

11 Tiago Rodrigues, «Chuchoter un peu plus fort», in Les Inrockuptibles, 26 de Julho de 2017, p. 27.

12 Retomando a expressão barthesiana, vale a pena ler o livro Os Pontos no Teatro Nacional D. Maria (coordenação de Alexandre Pieroni Calado, TDMII \& Bicho do Mato, 2017), também ele feito de fragmentos de um discurso amoroso e outras memórias. 


\section{REFERÊNCIAS BIBLIOGRÁFICAS}

Agamben, Giorgio (2010), Nudez, Lisboa, Relógio D’Água Editores.

cixous, Hélène / WAJSBrot, Cécile (2016), Une autobiographie allemande, Paris, Christian Bourgois. RODRIGUEs, Tiago (2015), «Préface», By Heart, Besançon, Les Solitaires Intempestifs.

- (2017), Sopro, Lisboa, TNDMII / Bicho do Mato. 